\title{
VENTILATION FOLLOWING INDUCTION OF GENERAL ANAESTHESIA BY THIOPENTONE*
}

\author{
Michel Germain, W.M. Wahba and D.M.M. Gillies
}

\begin{abstract}
We measured occlusion pressure, tidal volume, frequency, and the duration of the ventilatory phases in twenty-eight patients before and immediately after induction of anaesthesia by thiopentone. From these measurements we derived mean inspiratory flow rate and "effective" impedance to flow. Occlusion pressure was generally, but not universally, less after induction. Mean inspiratory flow rate was reduced due to a combination of smaller tidal volume and shorter duration of inspiration. This was noted in all twenty-eight patients, as was a clearcut increase in "effective" impedance to flow. These results suggest an important mechanical component to the reduced ventilation noted following induction of general anaesthesia.
\end{abstract}

Key Words: Anaesthetics, Intravenous, thiopentone: Ventilation, anaesthetics, effects of.

GaUTIER AND GaUDY reported that mean inspiratory flow rate $\left(\overline{\mathrm{V}}_{1}\right)$ was markedly decreased following an induction dose of thiopentone. ${ }^{1}$ They did not measure occlusion pressure, which is believed to be an index of central neuromuscular drive and the relationship of which to $\bar{V}_{I}$ is a useful, non-invasive means of examining pulmonary mechanics. ${ }^{2}$ The purpose of the present study was to determine the effects of thiopentone on $\bar{V}_{I}$ and $P^{\circ}$ to more clearly define the mechanism of reduced tidal breathing following the injection of thiopentone.

\section{METHODS}

\section{Theoretical Background}

Clarke and von Euler proposed that the output of the "respiratory centre" can be looked upon as consisting functionally of two components. ${ }^{3}$ The first component is an activity generator resulting in inspiratory flow and the other is a timer (or inspiratory "on-off" switch) which determines

*Presented in part at the Canadian Anaesthetists Society Meeting, June, 1980.

Michel Germain, M.D., Resident in Anaesthesia McGill University. W.M. Wahba, M.B., B.Ch., M.Sc. (McGill), F.R.C.P.(C)., C.S.P.Q. Associate Professor, McGill University; Anaesthetist, Queen Elizabeth Hospital of Montreal. Deirdre M.M. Gillies, M.B., Ch.B., F.R.C.P.(C)., C.S.P.Q. Associate Professor, McGill University; Anaesthetist-inChief, Queen Elizabeth Hospital of Montreal.

Address communications to: Dr. W.M. Wahba, Department of Anaesthesia, Queen Elizabeth Hospital of Montreal, 2100 Marlowe Avenue, Montreal, Québec H4A 3L6. 100 the relative duration of inspiration and expiration $\left(T_{i}\right.$ and $\left.T_{e}\right)$ and frequency. This information can be obtained by the simple expedient, proposed by Milic-Emili, ${ }^{2}$ of measuring tidal volume (VT) and the duration of the phases of breathing. The ratio of tidal volume to inspiratory duration $\left(\mathrm{Vr} / \mathrm{T}_{\mathrm{i}}\right)$ is called mean inspiratory flow rate $\left(\overline{\mathrm{V}}_{1}\right)$. The ratio of $T_{i}$ to total cycle time $\left(T_{\text {tot }}\right)$ is an index of the effective portion of the breathing cycle and is called the "duty cycle". If we divide 60 by $T_{\text {tot }}$ we obtain frequency. These derivations can then be used to render the classical minute ventilation (VE) equation more informative by the following modification:

$$
\begin{aligned}
\dot{V}_{E} & =V_{T} \times f \\
\text { Since } \quad V_{T} & =\left(\frac{V_{T}}{T_{i}} \times T_{i}\right)
\end{aligned}
$$

and

$$
\begin{aligned}
f & =\frac{60}{T_{\text {tot }}} \\
\dot{V}_{E} & =\frac{V T}{T_{i}} \times T_{i} \times \frac{60}{T_{\text {tot }}}
\end{aligned}
$$

which can be rearranged to:

$$
\dot{V} E=\frac{V_{T}}{T_{i}} \times \frac{T_{i}}{T_{t o t}} \times 60 .
$$

This form of the equation allows examination of the effect on tidal volume of a reduction in mean inspiratory flow rate with a constant $T_{i}$ and that of a shorter $T_{i}$ with an unchanged flow rate. In both instances VT will be reduced but the

Can. Anaesth. Soc. J., vol. 29, no. 2, March 1982 
mechanism is different (Figure 1). This equation also allows examination of the influence of duration on minute ventilation.

During quiet respiration there are phasic changes in airway pressure. The static subatmospheric pressure generated at the airway during intentional occlusion of the inspiratory limb of the breathing circuit is believed to be an index of central neuromuscular drive to ventilation. ${ }^{2}$ This occlusion pressure $\left(\mathrm{P}^{\circ}\right)$ is the potential energy available to generate inspiratory flow had there been no obstruction. As such, $\mathrm{P}^{\circ}$ indicates the pressure generated by neuromuscular drive and, therefore, takes into account both central drive and muscle contraction but cannot differentiate between them. A change in the configuration of the chest wall by changing muscle fibre length may influence the measurement of $\mathrm{P}^{\circ}$ even though central neurogenic drive is unchanged. In awake subjects, it is mandatory to use only the pressure generated prior to the patient's reaction (i.e. the pressure at $0.1 \mathrm{sec}$. ( $\mathrm{P}^{\circ} 0.1$ ).

The ratio of occlusion pressure to mean inspiratory flow rate can be called "effective" impedance because it relates pressure generated by the contracting ventilatory muscles to flow.

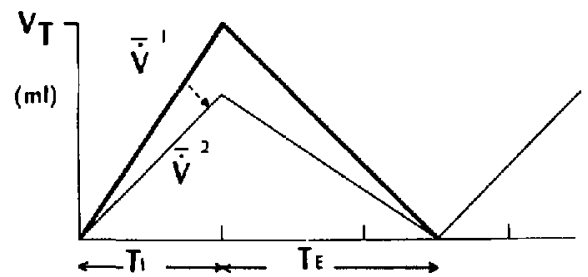

TIME (sec)

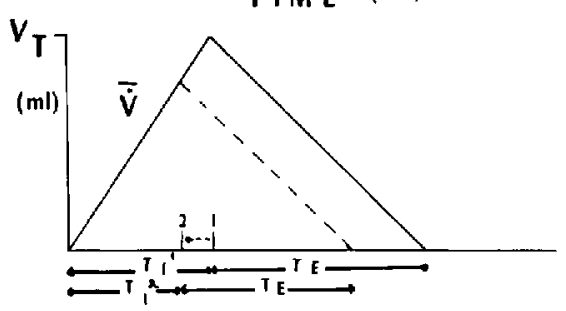

TIME (sec)

FIGURE 1 Influence of changes in Inspiratory Flow Rate and Inspiratory Duration on Tidal Volume 1(a) If mean inspiratory flow rate ( $\left.\bar{V}_{\mathrm{I}}\right)$ changes from 1 to 2 without any change in inspiratory duration $\left(\mathrm{T}_{\mathrm{i}}\right)$, measured tidal volume is decreased. $1(\mathrm{~b})$ If $\dot{\mathrm{V}}$ remains constant but $\mathbf{T}_{\mathbf{i}}$ is decreased, measured tida volume is less but by a different mechanism. Combination can, of course, occur.
This application of Ohm's law allows simple, non-invasive assessment of overall pulmonary mechanics.

\section{Patients Studied}

The measurements were made on 28 consenting adult patients (11 male, 17 female) scheduled for elective operations. * Age range was 17 to 82 years, with a mean age of 43 years. They were of normal body build (mean weight/height ratio was $0.393 \mathrm{~kg} \cdot \mathrm{cm}^{-1}$ ). The forced expiratory volume in one second to vital capacity $\left(\mathrm{FEV}_{1.0} / \mathrm{VC}\right)$ ratio was greater than 80 per cent in all subjects.

\section{Measurements: Sequence and Methods}

We made the measurements before and after induction of anaesthesia, as follows: (a) in the awake state with the subjects lying supine breathing room air, without premedication, on the day before the operation; (b) in the anaesthetized state (thiopentone). One hour after intramuscular premedication with promethazine $\mathrm{HCl}$ (12 to $25 \mathrm{mg}$ ) anaesthesia was induced with intravenous sodium thiopentone. The end point for induction was the loss of lash reflex. The mean dose required in these patients who had not received narcotic premedication was $7.44 \pm$ $0.31 \mathrm{mg} \cdot \mathrm{kg}^{-1}$. This is less than the dosage used by Gautier and Gaudy $\left(10 \mathrm{mg} \cdot \mathrm{kg}^{-1}\right.$ plus increments to maintain anaesthesia). One of us (M.G.) maintained a tight face mask fit and used a nasopharyngeal airway, if necessary. The measurements were made one and one-half minutes after the end of the injection of thiopentone, at which time the patients were breathing spontaneously

The experimental setup is shown in Figure 2. The fresh gas first went into a four litre reservoir bag, then through the occluding device, a Wright electronic respirometer and, finally, to the patient through a low resistance Ambu-Hesse valve attached to the face mask. The Wright respirometer was calibrated by the timed flow from an anaesthetic machine and the volume was doublechecked by displacement in a dry gas meter. Tidal volume was measured when fresh gas flow was interrupted at the anaesthetic machine (i.e. upstream from the reservoir bag). By switching the occluding device during expiration, the following inspiratory effort would be initiated at functional residual capacity (FRC) but without

* The investigational programme was approved by the Queen Elizabeth Hospital Ethics and Research Committee. 


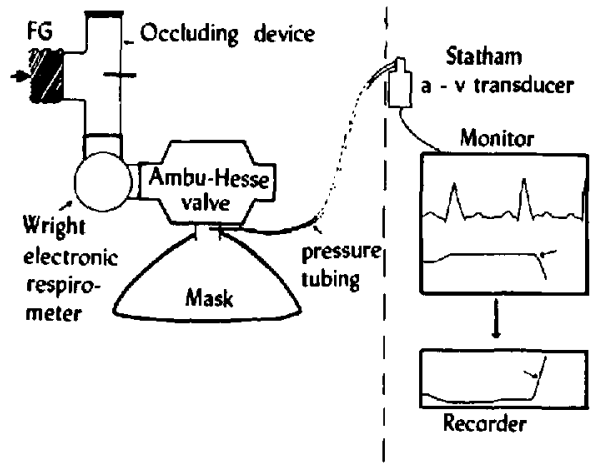

Figure 2 Breathing Circuit and Measuring Devices.

gas flow to the patient. The subatmospheric pressure generated by this inspiratory effort was measured by an appropriately calibrated Statham arterio-venous transducer, displayed on a Tektronix 412 monitor, and recorded on a singlechannel strip recorder with polarity changed to generate a positive deflection.

We measured airway occlusion pressure at functional residual capacity, inspired tidal volume and inspiratory and total cycle times.

Five to six measurements were made in each state. From these measurements we derived the mean inspiratory flow rate $\left(\mathrm{VT} / \mathrm{T}_{\mathrm{i}}\right)$, the "effective" impedance to flow $\left(\mathrm{P}^{\circ} 0.1 / \mathrm{VT} / \mathrm{T}_{\mathrm{i}}\right)$ and the ratio of inspiratory time to total cycle time $\left(T_{i} / T_{10}\right)$.

Because we noted a lack of consistency in the direction of change of occlusion pressure, we measured occlusion pressures before and after the injection of a small dose of thiopentone in seven intubated patients breathing enflurane (one per cent in $\mathrm{N}_{2} \mathrm{O}: \mathrm{O}_{2}$ at $9 \mathrm{l} / \mathrm{min}$.). This additional study was undertaken to determine whether subclinical upper airway obstruction influenced our results in the main study.

Statistical analysis was done by Student's t test for paired groups and by the least squares method for linear regression.

\section{Results (Table I)}

We found that the minute ventilation decreased by 26 per cent after induction; that was due to a clear-cut 40 per cent reduction in tidal volume which was not compensated for by the consistent increase in breathing frequency of about four breaths per minute.

The duration of inspiration $\left(T_{i}\right)$ following thiopentone decreased significantly $(P<0.01)$ to 75 per cent of that awake. The changes in VT and $T_{i}$ are graphically depicted as the reconstructed spirogram shown in Figure 3. The numbers on the inspiratory portion are the respective mean $V_{T} / T_{i}$ ratios.

Mean inspiratory flow decreased from $0.28 \pm$ $0.01 \mathrm{l} / \mathrm{sec}$ to $0.22 \pm 0.02 \mathrm{l} / \mathrm{sec}$ following induction of anaesthesia with thiopentone. This was a statistically significant $(P<.01) 21$ per cent reduction.

The ratio of inspiratory time to total cycle time $\left(T_{i} / T_{\text {tot }}\right)$ was 0.48 during the awake state; the ratio was 0.46 following induction of anaesthesia. This relatively small change was consistent and statistically significant.

The occlusion pressure measurements at $0.1 \mathrm{sec}$ are given in Table I. The reported value of occlusion pressure for the awake state is that of the first occlusion only, while that for the anaesthetized state is the average of the five measurements made.

The mean value of five occluded breaths following induction was $0.2 \pm 0.02 \mathrm{kPa}(2.00$ $\pm 0.18 \mathrm{cmH}_{2} \mathrm{O}$ ) (93 per cent of control values) which does not appear to be very different from the mean value of the first breath after apnoea: $0.19 \pm 0.02 \mathrm{kPa}\left(1.95 \pm 0.24 \mathrm{cmH}_{2} \mathrm{O}\right)$. The mean post-induction value was strongly biased by the marked increase in $P^{\circ} 0.1$ noted in six of the twenty-eight patients. There was no statistically significant difference between the measurements in the two states. We were unable to find any correlation between either the magnitude or the direction of change and age, sex, body configuration, thiopentone dose or period of apnoea.

In the seven patients given a small dose of thiopentone during anaesthesia, we noted an increase in $\mathrm{P}^{\circ}$ in four and a reduction in the others.

"Effective" impedance to flow increased sig-

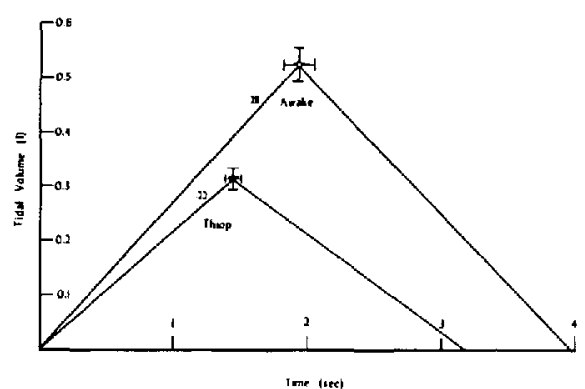

FIGURE 3 Reconstructed Spirograms. Following thiopentone induction $V T$ and $T_{i}$ were less. $V_{I}$ decreased significantly. 
TABLE I

RESULTS (Mean \pm Standard Error)

\begin{tabular}{|c|c|c|c|c|}
\hline & & \multicolumn{2}{|c|}{ Awake $\mathrm{n}=28$} & Thiopentone $n=28$ \\
\hline $\begin{array}{l}\text { A. Ventilation } \\
\text { Minute volume } \\
\text { Tidal volume } \\
\text { Frequency }\end{array}$ & $\begin{array}{l}1 / \mathrm{min} / \mathrm{m}^{2} \\
\mathrm{ml} / \mathrm{breath} \\
\mathrm{bpm}\end{array}$ & $\begin{array}{c}4.69 \\
526.0 \\
15.1\end{array}$ & $\begin{array}{l} \pm 0.21 \\
\pm 30 \\
\pm 0.8\end{array}$ & $\begin{array}{c}3.46 \pm 0.24^{*} \\
313.0 \pm 20 \dagger \\
18.9 \pm 0.7 \dagger\end{array}$ \\
\hline $\begin{array}{l}\text { B. Timing } \\
\text { Total cycle time } \\
\text { Inspiratory time } \\
\mathrm{T}_{\mathrm{i}} / \mathrm{T}_{\text {tot }}\end{array}$ & $\begin{array}{l}\left(\mathrm{T}_{\text {tol }}\right) \sec \\
\left(\mathrm{T}_{\mathrm{i}}\right) \sec \end{array}$ & $\begin{array}{l}3.98 \\
1.93 \\
0.48\end{array}$ & $\begin{array}{l} \pm 0.21 \\
\pm 0.12 \\
\pm 0.01\end{array}$ & $\begin{array}{l}3.18 \pm 0.12 \dagger \\
1.44 \pm 0.06 \dagger \\
0.46 \pm 0.01 \dagger\end{array}$ \\
\hline C. $\frac{\text { Mean inspiratory }}{\dot{V}}$ & $\begin{array}{l}\text { Iow Rate } \\
1 / \text { sec }\end{array}$ & 0.28 & \pm 0.01 & $0.22 \pm 0.02 \dagger$ \\
\hline $\begin{array}{l}\text { D. Occlusion Presst } \\
\mathrm{P}^{\circ} 0.1\end{array}$ & $\mathrm{kPa}_{2} \mathrm{O}$ & $\begin{array}{l}2.15 \\
0.215\end{array}$ & $\begin{array}{l} \pm 0.24 \\
\pm 0.024\end{array}$ & $\begin{array}{l}2.00 \pm 0.18 \\
0.20 \pm 0.018\end{array}$ \\
\hline $\begin{array}{l}\text { E. Effective Impeda } \\
\mathrm{cmH}_{2} \mathrm{O} / \mathrm{l} / \mathrm{sec} \text {. } \\
\mathrm{kPa} / \mathrm{l} / \mathrm{sec} \text {. }\end{array}$ & & $\begin{array}{l}7.68 \\
0.75\end{array}$ & $\begin{array}{l} \pm 0.73 \\
\pm 0.07\end{array}$ & $\begin{array}{l}9.1 \pm 1.2^{*} \\
0.89 \pm 0.18\end{array}$ \\
\hline
\end{tabular}

Statistical significance between means relative to preceding state: ${ }^{*} \mathrm{P}<.05$, $+\mathrm{P}<.01$.

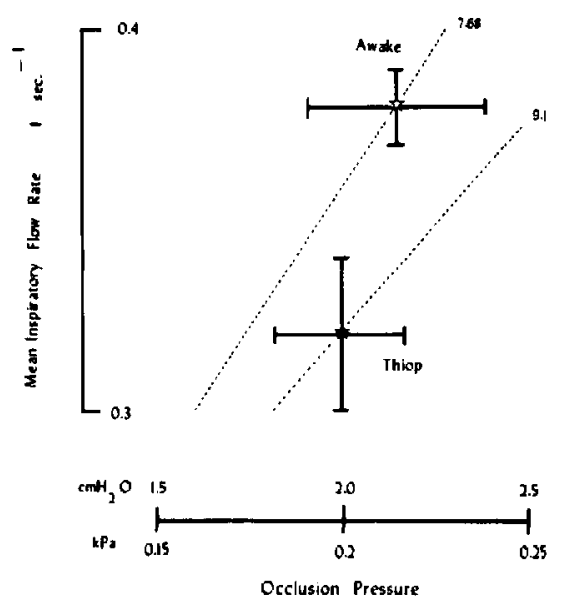

FIgure 4 Relationship between Occlusion Pressure and Inspiratory Flow Rate. Mean value \pm S.E.M. of mean inspiratory flow rate and occlusion pressure at $0.1 \mathrm{sec}$ are shown to illustrate graphically the relatively greater reduction in flow rate. The dotted lines are the isopleths of "effective" impedance. The increase in impedance was $1.42 \mathrm{~V} / \mathrm{sec} / \mathrm{cmH}_{2} \mathrm{O}$.

nificantly by 35 per cent after induction with thiopentone $(P<0.05)$ from a mean of $0.75 \pm$ $0.07 \mathrm{kPa}$ to a mean of $0.89 \pm 0.18 \mathrm{kPa} / \mathrm{sec}$ (7.68 \pm 0.73 to $9.1 \pm 1.2 \mathrm{cmH}_{2} \mathrm{O} / \mathrm{l} / \mathrm{sec}$ ) (Figure 4).

\section{Discussion}

In order to study the effects of thiopentone only we did not use a narcotic premedicant. ${ }^{4} \mathrm{We}$ are unaware of any study reporting ventilatory changes after promethazine.

The main observations made in this study are three in number. First, we confirmed that mean inspiratory flow rate is less after induction of anaesthesia. Second, occlusion pressure was on the whole unchanged, but was increased in seven patients. Third, inspiratory duration was markedly shortened after induction and $T_{i} / T_{\text {tot }}$ was consistently less but by a degree not likely to affect gas exchange significantly.

Before attempting to use that information to suggest a mechanism to explain reduced tidal breathing, we must first discuss the lack of consistency in direction of change of the occlusion pressure results. Occlusion pressure is taken as a valid representation of final central output and muscular response. ${ }^{2}$ It would indicate the effects of anaesthetics on either, but without differentiating whether the site of action is central or peripheral. Mean $P^{\circ} 0.1$ following induction was slightly less than control, But the increase in $P^{\circ} 0.1$ observed in six patients strongly biased the mean accounting for the lack of statistical significance between the measurements in the two states. If the upper airway is slightly obstructed due to loss of tone in the pharyngeal muscles, but without this being clinically evident, the pressure measured may be less than that actually generated because obstruction is down-stream of the measuring site. If that were so, then it would seem that an increase in $\mathrm{P}^{\circ}$ is the expected pattern. This increase may be due to carbon dioxide retention during ap- 
noea, or may reflect the response to the immediate increase in respiratory system elastance following thiopentone induction, as reported by Derenne. ${ }^{5}$ In the seven intubated patients which we studied during enflurane anaesthesia, we noted a lack of consistency in the direction of change in $\mathrm{P}^{\circ}$. We can only say, therefore, that in general mean $\mathrm{P}^{\circ} 0.1$ will be virtually unchanged after induction of anaesthesia.

In all our patients mean inspiratory flow rate was less following induction, in agreement with the results reported by Gautier and Gaudy. ${ }^{1}$ Despite the individual variability in direction and magnitude of change in $\mathrm{P}^{\circ}$ after induction, the mean value of "effective" impedance to flow in the present study was distinctly greater following induction of anaesthesia (Figure 4). The relationship between drive and flow can be analyzed by regression analysis. ${ }^{4}$ In the present study flow was $0.3 \mathrm{l} / \mathrm{sec} . / \mathrm{cmH}_{2} \mathrm{O}$ awake and $0.2 \mathrm{l} / \mathrm{sec} . / \mathrm{cmH}_{2} \mathrm{O}$ following induction, indicating a reduced ability to generate flow.

After a review of the literature Don ${ }^{6}$ concluded that the primary change in ventilatory mechanics during anaesthesia is "probably a mechanical phenomenon associated with an alteration of the position of the chest wall". It seems logical to ascribe our observations to this mechanism, assuming that the change occurs immediately after injection of thiopentone. Indeed, Macklem, Grassino, et al.,* noted a change in the resting position of the abdominal wall consistent with the cephalad shift of the diaphragm and reduced FRC, after induction of anaesthesia by thiopentone. This change in the FRC position may be sufficient to adversely affect the length-force and the tension-radius relationships of the diaphragm and to result in the changes we report.

Gautier and Gaudy' proposed that the changes in $T_{i}$ and $T E$ represent a stimulation of the "off" mechanism of the timing device. The factors

*Personal communication. influencing $T_{i}$ and $T E$ in man are not known. ${ }^{7}$ If the duration of the phases of ventilation in man is influenced by information coming from the chest wall, then any change in configuration or position of these structures may initiate a change in $T_{i}$ and $\mathrm{T}_{\text {tot }}$. For instance, prolonging the duration of expiration may serve to reduced expiratory flow rate in an attempt to keep the lung inflated and, therefore, to minimize a reduction in FRC.

In summary, the data we present suggest that reduced tidal volume following induction of anaesthesia with thiopentone is caused mainly by an increase in "impedance", and we suspect that the change in the resting position of chest wall is an important determinant of these results. Driving pressure $\left(\mathrm{P}^{\circ}\right)$ was, on the whole, unchanged, although there was variability in individual responses.

\section{REFERENCES}

1. Gautier, H. \& Gaudy, J.H. Changes in ventilatory patterns induced by intravenous anesthetic agents in human subjects. J. Appl. Physiol., 45(2): $171-176$ (1978).

2. Milic-Emili, J. Recent advances in the evaluation of respiratory drive. Int. Anesthesiol. Clinics, 15: 39-58 (1977).

3. Clark, F.J. \& VAN Euler, C. On the regulation of depth and rate of breathing. J. Physiol. London, 222: 267-295 (1972)

4. KNill, R., CosGrove, J.F., Olley, P. M. \& LEVISON, H. Components of respiratory depression after narcotic premedication in adolescents. Can. Anaesth. Soc. J., 23: 449-458 (1976).

5. DerenNe, J.P., Couture, J., Whitelaw, W.A. \& Milic-EmLli, J. Advances in Experimental Medicine and Biology, Vol. 99, New York: Plenum Press (1978). Interaction between the mechanical properties of the respiratory system and drive in the control of breathing of anesthetized man. Symposium on Regulation of Respiration during Sleep and Anesthesia. Edited by: Fitzgerald, R.S., Gautier, H., and Lahiri, S., pp. 105-116.

6. Don, H.F. The mechanical propertics of the respiratory system during anesthesia. Int. Anesthesiol. Clin., 15(2), 113-136 (1977).

7. Remmers, J.E. Analysis of ventilatory response. Chest, 70 (Supp.): 136-137 (1976).

RÉsumé

Nous avons mesuré la pression d'occlusion, le volume courant, la frequence respiratoire ainsi que la duréc des phases respiratoires chez 28 malades avant et après l'induction de l'anesthésie avec du thiopentone. A partir de ces données, nous avons calcule le debit moyen de l'inspiration et l'impédance effective à ce debit. En général, mais pas chez tous les malades, la pression d'occlusion était diminee après l'induction. Le debit moyen de l'inspiration était diminué grace à une diminution nette du volume courant et de la durée inspiratoire. L'impedance était plus élevée. Nous concluons que l'hypoventilation est partiellement causée par une altération de la mécanique ventilatoire. 